varicella zoster virus vasculopathies. Clinical, CSF, imaging, and virologic features. Neurology March 11, 2008;70:853-860). (Reprints: Dr DH Gilden, Department of Neurology, Mail Stop B182, University of Colorado Health Sciences Center, 4200 E $9^{\text {th }}$ Ave, Denver, CO 80262).

COMMENT. VZV is a possible cause of stroke in children and adults, even without a history of rash. Prior rash was absent in $29 \%$ of children and in $40 \%$ of the total group. Symptoms of vasculopathy can be delayed up to 3 months after the rash in children, 4 months in adults. CSF pleocytosis was present in the majority (86\%) of children, but absent in $33 \%$ of the total group.

Acute infection, viral or bacterial, is a risk factor for cerebral infarction and stroke in all age groups. The reported prevalence of infection in the week preceding ischemic stroke ranges from $10 \%$ to $35 \%$. Influenza vaccination has been correlated with a lower risk of stroke. (Emsley HCA, Hopkins SJ. Lancet Neurology April 2008;7:341-353).

Herpes zoster live-attenuated vaccine in elderly subjects was effective and increased VZV-T cell-mediated immunity within 6 weeks after vaccination. Boosting immunity by vaccination should protect older adults against herpes zoster and postherpetic neuralgia, at least 4 years or longer. (Levin MJ et al. J Infect Dis March 15, 2008;197:825835).

\title{
BRAIN MALFORMATIONS
}

\section{CLASSIFICATION OF CORTICAL BRAIN MALFORMATIONS}

Clinical, radiological, and genetic classifications of 113 cases of malformations of cortical development (MCD) were evaluated at the Erasmus Medical Center-Sophia Children's Hospital, Rotterdam, the Netherlands. Diagnosis was confirmed retrospectively in 48 patients during a 10-year period, and prospectively in 65 during only 4 years. Increased alertness or improved brain imaging might have accounted for the more recent higher prevalence of diagnosis of MCD. Disorders of proliferation (eg. congenital microcephalies) occurred in 11, disorders of migration (lissencephaly/heterotopia) in 51, disorders of cortical organization (eg schizencephaly) in 49, and MCD secondary to inborn errors of metabolism in 2. An etiologic diagnosis was established in $45(40 \%)$ cases. In 21 patients (19\%) molecular and/or genetic confirmation was established (eg. Miller-Dieker syndrome, inborn error of metabolism). Genetic defect was unknown in 17 (15\%). A gestational insult had occurred in 7 (6\%). In 34 of the remaining 68 patients, a genetic disorder was suspected based on multiple anomalies, family history, or consanguinity. More definitive diagnosis of MCD would lead to improved patient care and genetic counseling. (de Wit MCY, Lequin $\mathrm{MH}$, de Coo IFM et al. Cortical brain malformations. Effect of clinical, neuroradiological, and modern genetic classification. Arch Neurol Mar 2008;65:358-366). (Respond: Grazia MS Mancini MD PhD, Department of Clinical Genetics, Erasmus Medical Center, PO Box 1738, 3000 DR Rotterdam, the Netherlands. E-mail: mancini@erasmusmc.nl).

COMMENT. See Sarnat HB. In Progress in Pediatric Neurology III, Chicago, PNB, 1997;365-9; and Norman MG et al. Congenital Malformations of the Brain. New York, Oxford University Press, 1995;452 pages, for excellent reviews of MCD advances. 